\title{
Phase behavior of Brazilian stock tank oil and carbon dioxide at reservoir conditions: experiments and thermodynamic modeling
}

\author{
C. B. K. Araújo ${ }^{1}$ - F. O. Capitelli ${ }^{1} \cdot$ K. Rajagopal ${ }^{2} \cdot$ M. L. Corazza ${ }^{1} \cdot$ \\ P. M. Ndiaye ${ }^{2}$
}

Received: 11 April 2014/Accepted: 22 March 2015/Published online: 7 April 2015

(C) The Author(s) 2015. This article is published with open access at Springerlink.com

\begin{abstract}
In the first part of this work, phase behavior data of Brazilian stock tank oil and carbon dioxide are reported. The statical synthetical method was used. This technique consists of injecting known amounts of stock tank oil and carbon dioxide in an equilibrium cell, from which the bubble point is detected by an infrared device for a given temperature and then the corresponding pressure is recorded. In the second part of this work, thermodynamics modeling of experimental data was performed. The modified Peng-Robinson equation of state was used for predicting saturation pressure. A strategy for the estimation of the $\mathrm{C}_{20+}$ fraction is discussed by considering the critical pressure along with the Chueh Prausnitz binary interaction parameters. Results show that the saturation pressure of the system Marlim/ $/ \mathrm{CO}_{2}$ is strongly affected by the concentration of carbon dioxide, while temperature exhibits unexpected effects on the phase transition pressure.
\end{abstract}

Keywords Carbon dioxide - Heavy oil - Phase behavior . Thermodynamics modeling

P. M. Ndiaye

papa@eq.ufrj.br; papamatar00@gmail.com

1 Departamento de Engenharia Química, Centro Politécnico, Universidade Federal do Paraná, Curitiba 81531-980, Brazil

2 Departamento de Engenharia Química, Escola de Química, Universidade Federal do Rio de, CP 68542, Av. Horácio Macedo, 2030 Ed. do Centro de Tecnologia, Bloco E-sala 209, Rio de Janeiro, RJ CEP 21941-909, Brazil

\section{Introduction}

A significant number of enhanced oil recovery (EOR) techniques focus on increasing the displacement efficiency as their main recovery mechanism by injecting carbon dioxide. Carbon dioxide flooding is among the most promising EOR methods in heavy oil reservoirs and has been successfully used in a number of worldwide basins where other enhanced oil recovery (EOR) techniques are not applicable (Danesh 1998). Carbon dioxide becomes supercritical when injected under field conditions, and as a consequence it can recover more oil with the additional benefit of considerably reducing greenhouse gas emissions. Several factors affect the mobilization efficiency. These factors include rock geometry, pore structure, flooding rate and fluid properties (Yuan et al. 2003). During the flooding process, $\mathrm{CO}_{2}$ is injected into the formation to highly enhance the mobility of the contacted oil, thus promoting its displacement towards the production. Oil mobility is improved because the solubility of $\mathrm{CO}_{2}$ in oil causes both a reduction of viscosity and increases the oil volume (Pedersen et al. 1989). The solubility of $\mathrm{CO}_{2}$ in oil fraction constitute key factor for EOR successful projects and thus, the study of phase behavior of the crude oil/ $/ \mathrm{CO}_{2}$ is the first and fundamental step for understanding oil recovery mechanism in petroleum reservoirs. Knowledge about the phase behavior of crude in solvent of low molecular weight and petroleum fluids is important in the petroleum industry, for primary production (Pedersen et al. 1989), enhanced oil recovery, gas injection (Pedersen et al. 1989) and re-injection (Yuan et al. 2003), pipeline transportation, deasphalting process and petroleum processing and refining. The maximum oil production can be reached when well is operated at pressure close to the saturation pressure (Katz and Firoozabadi 1978). Therefore, the knowledge of the 
saturation pressure (phase transition or first bubble point) is a fundamental step for oil production. In this work, we report experimental phase transition data of a mixtures composed by a Brazilian stock tank oil and carbon dioxide in a temperature range $45-120{ }^{\circ} \mathrm{C}$ and over a carbon dioxide concentration range from 16.6 to $35 \%$ in weight.

\section{Experimental section}

\section{Materials}

The carbon dioxide used in this work was supplied by White Martins S.A at purity higher than $99.5 \%$. The stock tank oil is a heavy crude petroleum commonly known as Marlim petroleum (API degree between 15 and 20) and was kindly provided by Cenpes/Petrobras-Brazil. Table 1 presents the compositional analysis of the marlim oil used in this work.

\section{Apparatus and experimental procedure}

The experimental scheme used in this work is based on the static synthetic method shown in Fig. 1.

The equilibrium cell assembly of the cell begins with the adjustment of the piston o-rings tightness. This step requires special care, because piston tightening should not be weak (This will allow fluid passage into the cell and changing the overall composition) and at the same time should not be too strong to avoid a pressure drop between the sample and the process line.

The experimental procedure begins by loading $\mathrm{CO}_{2}$ into the syringe pump chamber. Since at room temperature

Table 1 Compositional analysis of Marlim oil

\begin{tabular}{|c|c|}
\hline Component & Mass \% \\
\hline C5 & 0.068 \\
\hline C6 & 0.36 \\
\hline C7 & 2.229 \\
\hline $\mathrm{C} 8$ & 5.962 \\
\hline C9 & 7.321 \\
\hline $\mathrm{C} 10$ & 7.44 \\
\hline $\mathrm{C} 11$ & 5.238 \\
\hline $\mathrm{C} 12$ & 5.605 \\
\hline $\mathrm{C} 13$ & 6.007 \\
\hline $\mathrm{C} 14$ & 5.319 \\
\hline $\mathrm{C} 15$ & 7.066 \\
\hline C16 & 5.698 \\
\hline $\mathrm{C} 17$ & 3.758 \\
\hline C18 & 4.759 \\
\hline C19 & 3.222 \\
\hline $\mathrm{C}_{20+}$ & 29.95 \\
\hline
\end{tabular}

(298 K) $\mathrm{CO}_{2}$ is a gas, the mere opening of the valve of the cylinder containing the gas is not enough to move a sufficient amount of solvent into the syringe pump chamber. Usually, with the cylinder valve and $\mathrm{V}_{1}$ opened for about 30 min and $\mathrm{V}_{2}$ closed, the temperature of the syringe pump chamber is kept at $283 \mathrm{~K}$. This arrangement allows a natural flow from room temperature (gas cylinder) up to the reduced temperature range (syringe pump). While the chamber is being filled, the cell assembly can be started by inserting a precise amount of stock tank oil into the cell together with the magnetic bar. The cell is then closed and connected to the process line. Keeping $\mathrm{V}_{5}, \mathrm{~V}_{6}$, and $\mathrm{V}_{7}$ closed, $\mathrm{V}_{2}, \mathrm{~V}_{3}$ and $\mathrm{V}_{4}$ are opened. With $\mathrm{V}_{1}$ closed, the entire line is pressurized using the syringe pump and stabilized at $15 \mathrm{MPa}$ and $283 \mathrm{~K}$. The stabilization of the system (zero pump flow) requires about ten to $15 \mathrm{~min}$, and should be done carefully because any trace of flow may lead to systematic errors on the determination of volume of injected $\mathrm{CO}_{2}$. Once the system is stabilized, the volume of $\mathrm{CO}_{2}$ inside the syringe pump chamber is recorded and a given volume of gas is injected into the cell through the micrometric valve $\mathrm{V}_{7}$. Once the $\mathrm{CO}_{2}$ injection process concludes, the pressure of the system is lowered to $5 \mathrm{MPa}$ and the valve $\mathrm{V}_{6}$ is opened (keeping $\mathrm{V}_{1}, \mathrm{~V}_{7}, \mathrm{~V}_{5}$ closed and $\mathrm{V}_{2}, \mathrm{~V}_{3}, \mathrm{~V}_{4}$ opened). A sequence of procedures aiming to obtain a monophasic system is then started. The system is continuously stirred and the pressure inside the cell gradually increased until the condition of a single-phase system is obtained. Then the saturation pressure of the system is measured at four temperatures (namely: 363, 373, 383 and $393 \mathrm{~K}$ ). For this purpose, the heating device is turned on and monitored by a PID controller device. For a given temperature, the pressure is gradually reduced though the syringe pump controller at a rate $0.05 \mathrm{MPa}$ per minute. This rate of pressure reduction is sufficient to minimize the mass transfer resistance.

For saturation pressure measurements, the light source from the lateral window of the equilibrium cell is turned on and a digital microscope with infrared device accurately allows recording precise phase transitions at low (or even without eye) visibility. The digital microscope used in this work can magnify the image of the equilibrium cell up to 200 times with high resolution. This latter detail is especially useful, not only for phase transition observation but also for detecting solid phase precipitation.

\section{Thermodynamic modeling}

\section{The modified Peng-Robinson equation}

The Peng-Robinson equation of state (EOS) (Peng and Robinson 1976) is given by 


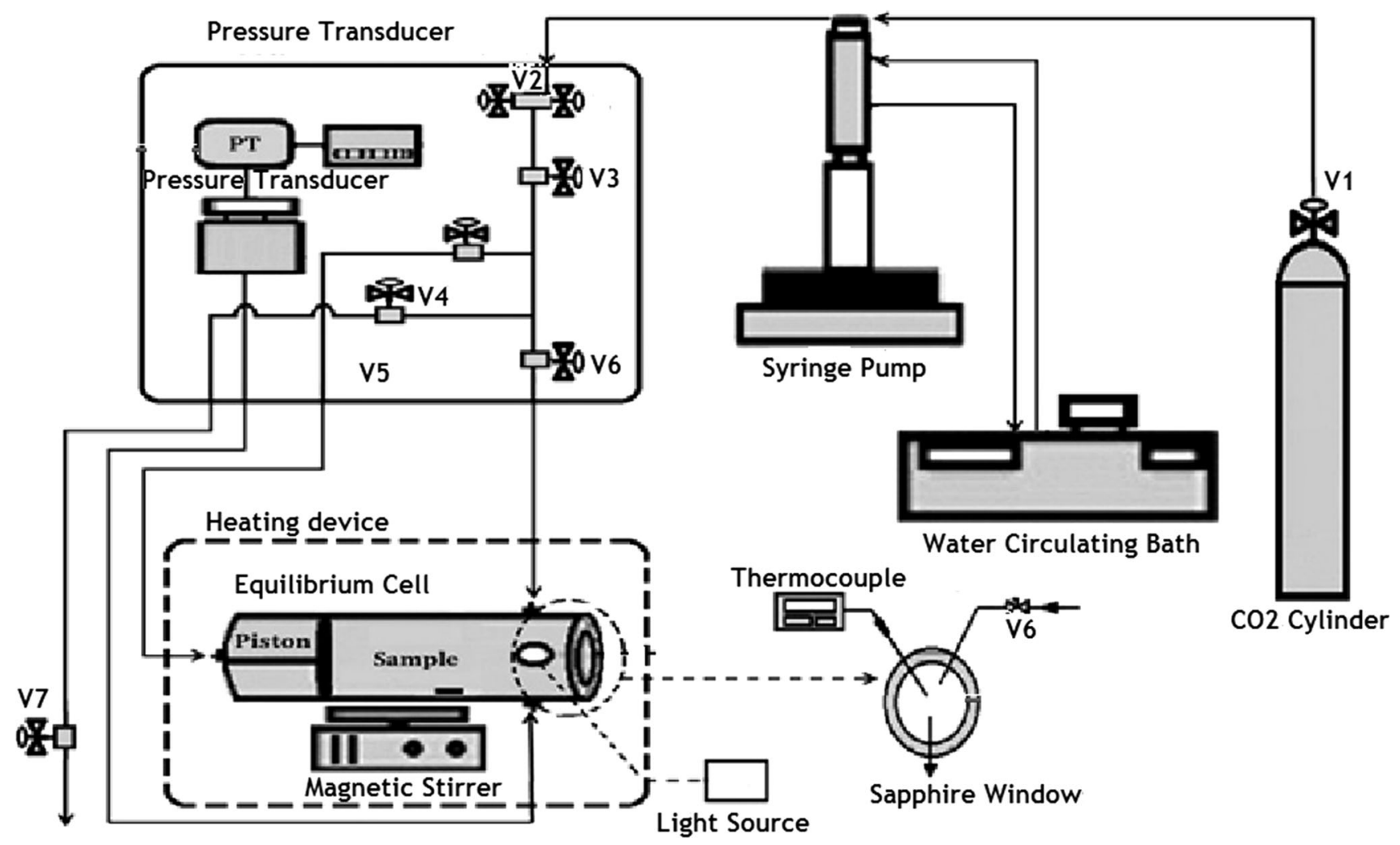

Fig. 1 Scheme of the static synthetic method used in this work. $\mathbf{V}_{\mathbf{1}}$ Needle valve (HIP, Model 15-12AF2). When opened, allows the flow of $\mathrm{CO}_{2}$ or from the cylinder to the chamber of the syringe pump. $\mathbf{V}_{\mathbf{2}}$ Two-way valve (HIP, Model 15-AF1). This valve can be connected to one or two syringe pumps and is used to inject $\mathrm{CO}_{2}$ or gas from the syringe pump into the process line. $\mathbf{V}_{\mathbf{3}}, \mathbf{V}_{\mathbf{4}}$ and $\mathbf{V}_{\mathbf{6}}$ Needle valves (Autoclave Engineers, Model MVE 1001). The function of these valves is to cut or allow the flow in a given line. The valve $\mathrm{V}_{4}$ is used to isolate the unit from the pressure pump during assembly and disassembly of the equilibrium cell, and thus avoid gas or $\mathrm{CO}_{2}$ loss. The valve $\mathrm{V}_{3}$ is used to isolate the pressure transducer during the discharge process of the system and prevent any solute entry into the pressure transducer diaphragm if an inadequate procedure happens during the discharging process. The valve $\mathrm{V}_{6}$ has the function of

$P=\frac{\mathrm{RT}}{v-b}-\frac{a}{[v(v+b)+b(v-b)]}$

where $a$ and $b$ are the attraction parameter and the covolume, respectively

$b=0.07780 \frac{\mathrm{RT}_{\mathrm{c}}}{P_{\mathrm{c}}}$

$a=\frac{0.45724 R^{2} T_{\mathrm{c}}^{2}}{P_{\mathrm{c}}}\left[1+f\left(\omega, T_{\mathrm{r}}\right)\right]^{2}$

$f\left(\omega, T_{\mathrm{r}}\right)=\left(0.3764+1.5422 \omega-0.2699 \omega^{2}\right)\left(1-T_{\mathrm{r}}^{0.5}\right)$

where $T_{\mathrm{c}}, P_{\mathrm{c}}$ and $\omega$ are the critical temperature, the critical pressure and the acentric factor, respectively, and $T_{\mathrm{r}}$ is the reduced temperature $\left(T_{\mathrm{r}}=\frac{T}{T_{\mathrm{c}}}\right)$. avoiding any fluid flow to the piston during the gas or the $\mathrm{CO}_{2}$ injection into the cell. When this valve is opened, the pressurization or depressurization of the sample takes place through the piston displacement. PT e and MP are respectively a pressure transducer and pressure indicator. $\mathbf{V}_{\mathbf{7}}$ Needle valve (Autoclave Engineers, Model MVE 1001). This valve is used as feeding valve to inject a compressed fluid into the cell and is suitable for a rigorous control of the fluid flow being injected. $\mathbf{V}_{\mathbf{5}}$ Flush needle valve (HIP Model $1511 \mathrm{AF} 1)$. Used for flushing the system and the cell depressurization. This valve is also used for gas removing during the two-stage recombination process. $\mathbf{V}_{\mathbf{8}}$ One-way valve (HIP Model 15-41AF1). This valve allows the flow in one way and is used together with $V_{5}$ to remove the gas from the pressurized system to the ambient, during the recombination process

For components with large acentric factor value $(\omega>0.49)$, the following function is used

$$
\begin{aligned}
f\left(\omega, T_{\mathrm{r}}\right)= & \left(0.379642+1.48503 \omega-0.164423 \omega^{2}\right. \\
& \left.-0.016666 \omega^{3}\right)\left(1-T_{\mathrm{r}}^{0.5}\right)
\end{aligned}
$$

For $\mathrm{P}-\mathrm{V}-\mathrm{T}$ data correlations, the Peng-Robinson (PR) equation of state (EOS) represents a significant improvement when compared to the Soave-RedlichKwong (SRK) equation of state. While the SRK equation predicts that the critical compressibility factor $Z_{\mathrm{c}}$ is 0.333 and, consequently, poor liquid density predictions are obtained; the value of $Z_{\mathrm{c}}$ predicted by the PR EOS is 0.307. It is important to emphasize here that the experimental value of $Z_{c}$ for hydrocarbons is 0.29 or less. 
A third parameter-usually referred as $c$ or volume shift parameter-could be then introduced through the following relation:

$v^{(3)}=v^{2}-\sum_{i=1}^{\mathrm{nc}} x_{i} c_{i}$

where $v^{(3)}$ is the corrected third parameter volume while $v^{(2)}$ is the volume predicted by the two parameter equation. The shift in volume leads to a convenient reduction of the $Z$ factor. The values of $c_{i}$ are commonly calculated by comparing the observed liquid molar volume at standard condition of temperature $\left(T_{\mathrm{st}}\right)$ and pressure $\left(P_{\mathrm{st}}\right)$ with that obtained by the two parameter EOS at the same conditions. The difference determines the $c_{i}$ for component $i$.

$c_{i}=v^{\mathrm{EOS}}\left(P_{\mathrm{st}}, T_{\mathrm{st}}\right)-v^{\mathrm{OBS}}\left(P_{\mathrm{st}}, T_{\mathrm{st}}\right)$

The shift parameter are usually defined as a ratio

$s_{i}=\frac{c_{i}}{b_{i}}$

where $b_{i}$ is the pure component co-volume as defined above.

The volume shift correction has no effect on the isofugacity condition and thus, it does not affect other predicted equilibrium properties like the saturation pressure and $K$ values.

Application of the EOS to fluid mixtures requires a mixing rule to describe the mixture from the properties of its pure constituents. For hydrocarbon systems, the van der Waals mixing rules are commonly used

$a=\sum_{i=1}^{n} \sum_{j=1}^{n} x_{i} x_{j} a_{\mathrm{ij}}$

$a_{\mathrm{ij}}=\left[\left(a_{i} a_{j}\right)^{0.5}\right]\left(1-k_{\mathrm{ij}}\right)$

$b=\sum_{i=1}^{\mathrm{nc}} x_{i} b_{i}$

where $b_{i}$, and $a_{i}$ are the pure component parameters given by Eqs. (2) and (3), respectively $x_{\mathrm{i}}$ represent the molar fraction of component $\mathrm{i}$.

\section{EOS tuning}

The $k_{\mathrm{ij}}$ are usually referred as Binary Interaction Parameters (BIP) and are usually calculated by parameterizing the EOS with experimental $K$ values (Katz and Firoozabadi 1978). For hydrocarbon systems, BIPs are commonly set to zero, except for describing interactions between non-hydrocarbon and hydrocarbon and between light and heavy hydrocarbons.

An alternative method for evaluating BIPs was proposed by Chueh and Prauznitz (1968):

$k_{\mathrm{ij}}=A\left[1-\left(\frac{2\left(v_{\mathrm{ci}} v_{\mathrm{cj}}\right)^{\frac{1}{6}}}{v_{\mathrm{ci}}^{\frac{1}{3}} v_{\mathrm{cj}}^{\frac{1}{3}}}\right)^{B}\right]$

where $v_{\mathrm{ci}}$ is the critical molar volume of the component $\mathrm{i}$. The value of B is commonly fixed to 6 and the coefficient $A$ is adjusted to match measured saturation pressures of the mixture. Since correlations for critical pressure are in general less accurate than correlations for critical temperature, the critical pressure of the $\mathrm{C}_{20+}$ fraction together with the binary interaction parameter $\mathrm{C}_{20+} / \mathrm{CO}_{2}$ was used as regression variables to fit experimental pressure saturation data with the modified Peng-Robinson EOS. Regression was done at fixed $\mathrm{CO}_{2}$ composition (30\% in mass). Then, the resulting parameters were used to calculate saturation pressure at other concentrations (20, 2530 and $35 \%$ ).

\section{Results and discussion}

Figure 1 shows pictures of the two-phase system (1), monophasic system (2) and the arising of the first bubble (3). Results are presented in Table 2 and in Figs. 2 ( $\mathrm{P}-\mathrm{w}$ diagram) and 3 (P-T diagram). As can be observed, the phase transition detection device used is very suitable. At this stage and prior to any further information, it is

Table 2 Experimental saturation pressure of marlim oil/ $\mathrm{CO}_{2}$ system

\begin{tabular}{|c|c|c|c|c|c|}
\hline \multirow[t]{2}{*}{$T[K]$} & \multicolumn{5}{|c|}{$\mathrm{CO}_{2}$ mass $\%$} \\
\hline & $\begin{array}{l}16.5 \\
P^{\text {sat }}[\text { bar }]\end{array}$ & 20 & 25 & 30 & 35 \\
\hline $318.15 \pm 0.1$ & $64.4 \pm 2$ & $85 \pm 1.8$ & & $179.1 \pm 0.1$ & \\
\hline $343.15 \pm 0.2$ & $91.7 \pm 1.5$ & $112.5 \pm 2$ & & $196.35 \pm 0.3$ & \\
\hline $363.15 \pm 0.2$ & $108 \pm 1.6$ & $145 \pm 2$ & $191 \pm 1.8$ & $231 \pm 0.2$ & $298 \pm 1.8$ \\
\hline $373.15 \pm 0.3$ & $115 \pm 2.3$ & $152 \pm 2.1$ & $196 \pm 1.8$ & $239 \pm 0.4$ & $310 \pm 1.8$ \\
\hline $383.15 \pm 0.4$ & $121 \pm 2.1$ & $159 \pm 1.7$ & $204 \pm 1.8$ & $251 \pm 0.1$ & $320 \pm 1.8$ \\
\hline $393.15 \pm 0.5$ & $127 \pm 1.8$ & $166 \pm 1.9$ & $212 \pm 1.8$ & $259 \pm 0.3$ & $330 \pm 1.8$ \\
\hline
\end{tabular}



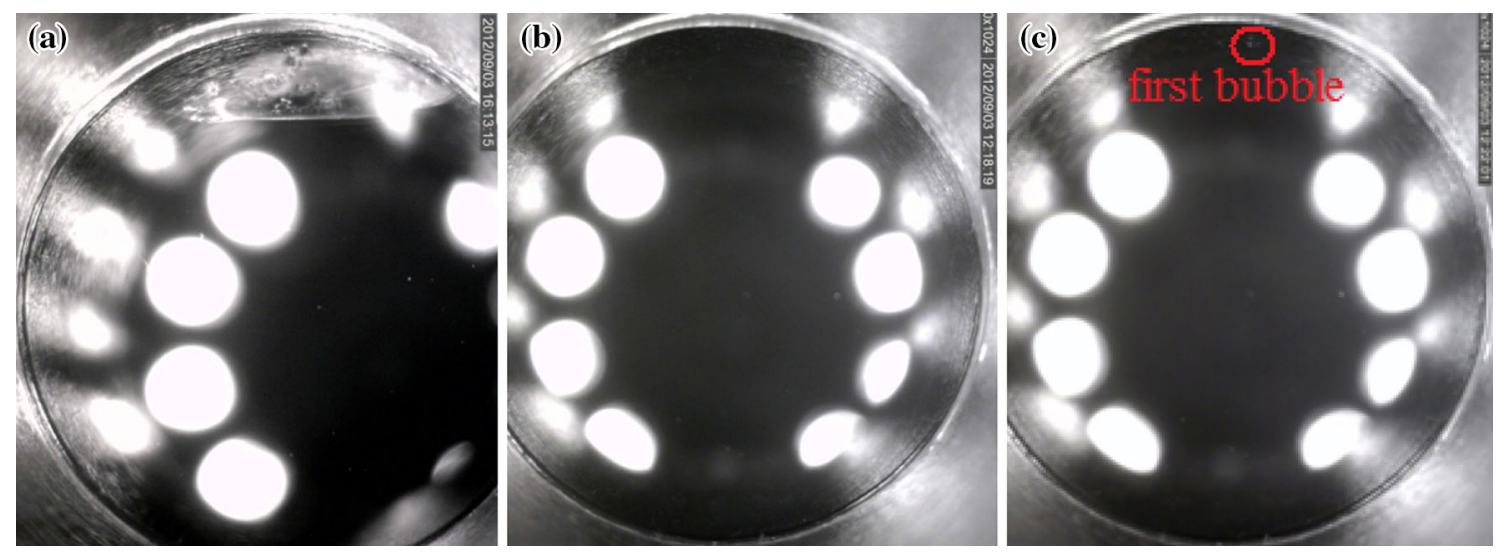

Fig. 2 Phase transition recorded from infrared microscope device: a two-phase system, b monophasic system, c first bubble

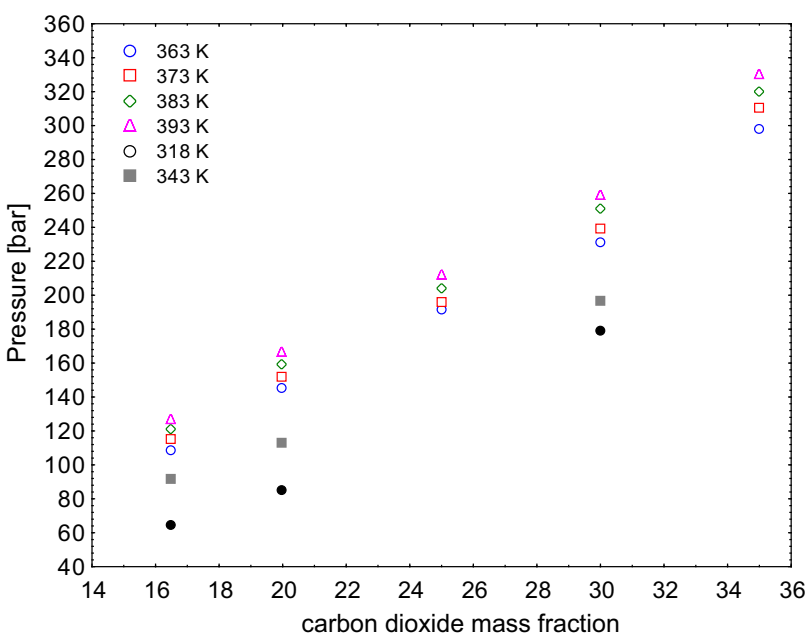

Fig. $3 \mathrm{P}-\mathrm{w}$ diagram of the system marlim oil/carbon dioxide at several temperatures

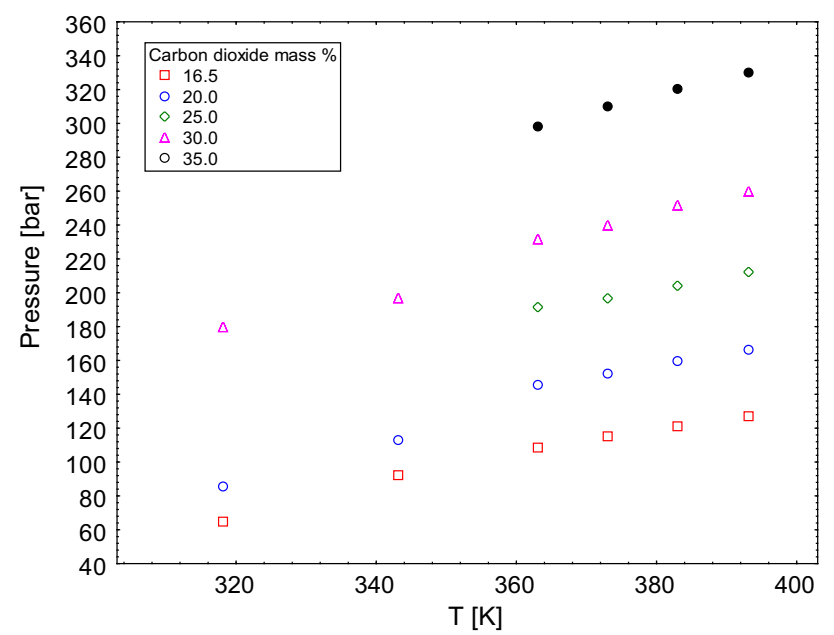

Fig. 4 P-T diagram of the system marlim oil/carbon dioxide at several temperatures

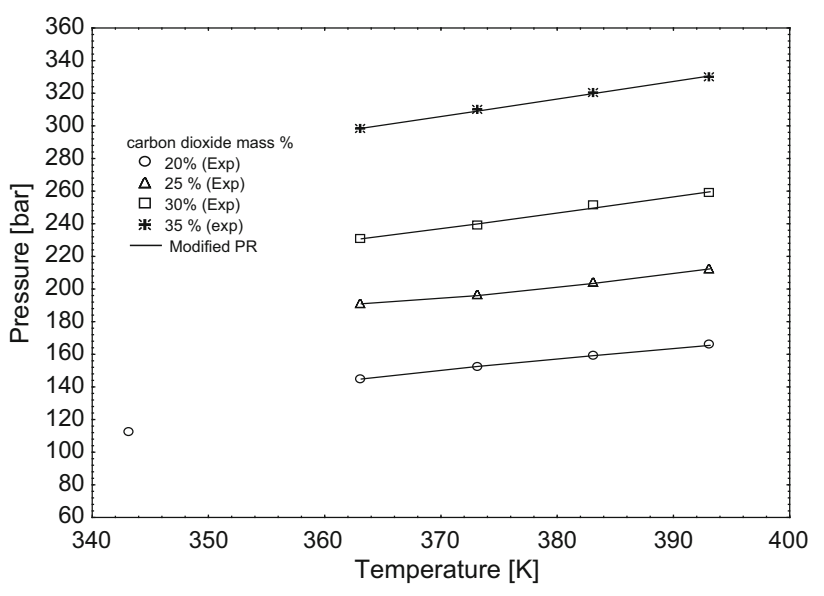

Fig. 5 Comparison of experiments and thermodynamics model

important to highlight that this direct measurement of saturation pressures without any additional treatment of images is reported by the first time in literature (Fig. 3).

Comparison of Figs. 3 and 4 shows that the effect of temperature on phase transition pressures is smooth when compared to the effect of carbon dioxide concentration. For example, at constant $\mathrm{CO}_{2}$ concentration, a difference of 10 degrees in temperature leads to a change of 9 bars on the phase transition pressure, while the expected pressure change is 20 bar. In contrast, at constant temperature, a difference of $5 \%$ in $\mathrm{CO}_{2}$ concentration leads to a variation of 50 bar. Accordingly, the phase behavior of the system is highly affected by $\mathrm{CO}_{2}$ concentration.

As can be observed from Fig. 5, the three-parameter Peng-Robinson Equation of state exhibited a good performance in correlating the saturation pressure data. This means the strategy of tuning the equation was successful.

At carbon dioxide concentrations higher than $25 \%$, an unusual behavior was observed with the appearance of small like solid segregated particles in the liquid phase 
Fig. 6 Like solid Particle segregation of the system Marlim oil/ $/ \mathrm{CO}_{2}$ at carbon dioxide mass fraction higher than 0.25
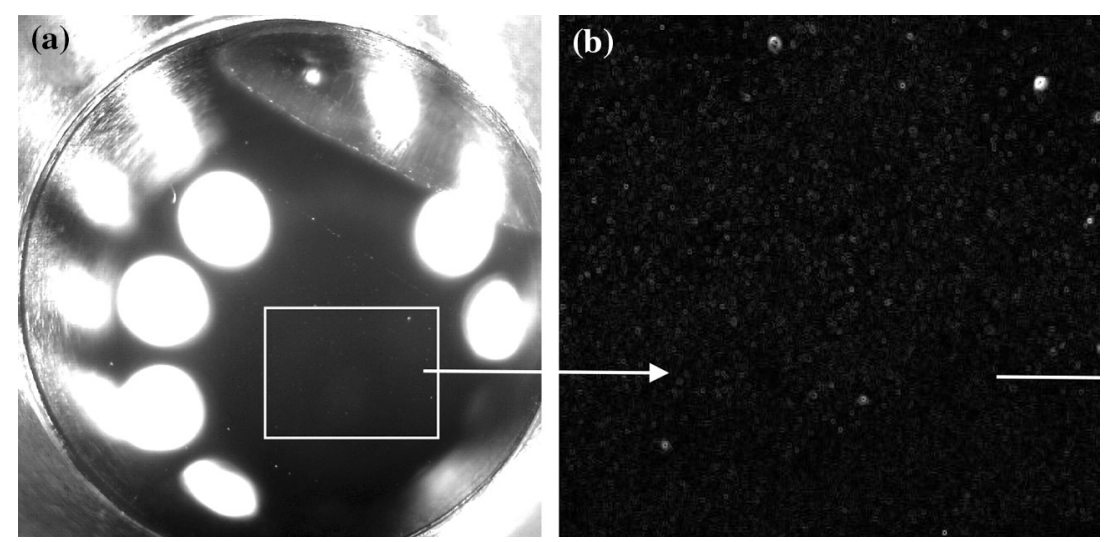

(Fig. 6) followed by the dissolution of these particles if the system is kept under agitation during $6 \mathrm{~h}$. This behavior has no effect on transition pressure. Figure 6a shows the vapor liquid equilibrium of Marlim oil/ $\mathrm{CO}_{2}$ with a mass fraction $30 \%$ of $\mathrm{CO} 2$ at temperature equal to $383 \mathrm{~K}$ and pressure equal to 200 bar. Figure 6a shows a zoom of the liquid phase with the appearance of solid particles.

\section{Conclusions}

In this work, experimental data and thermodynamic modeling of the system with carbon dioxide/Marlim at high temperature and high pressure were presented. These data are useful for EOR investigations. Result shows that the temperature has a minor effect to the saturation pressure of the system in contrast to the carbon dioxide concentration which showed stronger influence. The modified PengRobinson EOS tuned with the critical pressure of $\mathrm{C}_{20+}$ was suitable to correlate the saturation pressure of the system marlim oil/carbon dioxide.
Open Access This article is distributed under the terms of the Creative Commons Attribution 4.0 International License (http:// creativecommons.org/licenses/by/4.0/), which permits unrestricted use, distribution, and reproduction in any medium, provided you give appropriate credit to the original author(s) and the source, provide a link to the Creative Commons license, and indicate if changes were made.

\section{References}

Chueh PL, Prausnitz JM (1968) Calculation of high-pressure vaporliquid equilibria. Ind Eng Chem 60(3):34-52

Danesh A (1998) PVT and phase behaviour of petroleum reservoir fluids. In: Developments in petroleum science, vol 47. Elsevier

Katz DL, Firoozabadi A (1978) Predicting phase behavior of condensate/crude oil system, using methane interaction coefficients. JPT:1649-1655

Pedersen KS, Fredenslund A, Thomassen P (1989) Properties of oils and natural gases. Gulf Publishing Company, Houston

Peng DY, Robinson DB (1976) A new two constant equation of state. Ind Chem Fundam 15(1):59-64

Yuan S, Ye J, Sun Z (2003) Theory and practice in gas-condensate reservoir development. China Petroleum Industry Press, Beijing 